\title{
Influência de diferentes protocolos de exercício e da dieta hiperlipídica sobre o sistema endocanabinóide de ratos
}

https://doi.org/10.11606/issn.1981-4690.v35i1p159-175

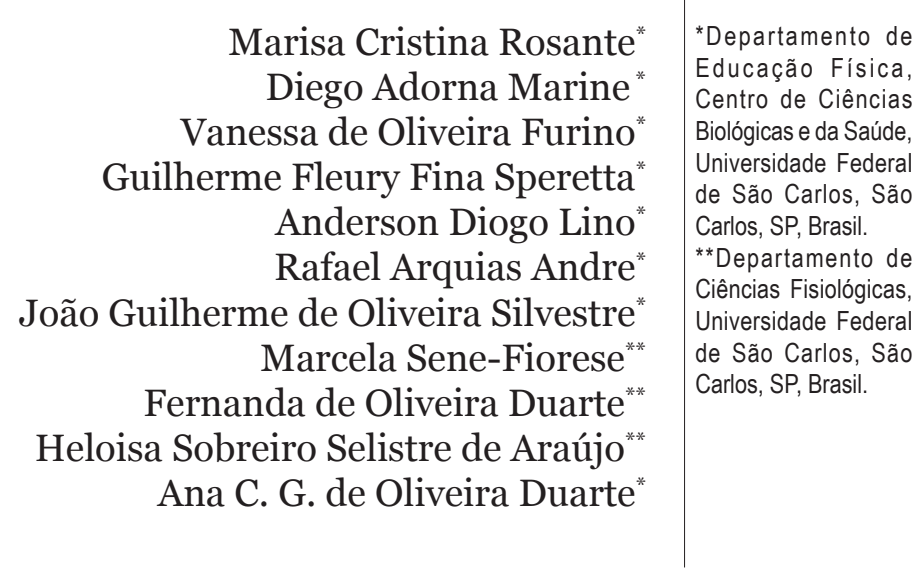

Marisa Cristina Rosante* ação Fisica, de Ciências Universidade Federa de São Carlos, São **Departamento de Ciências Fisiológicas, sidade Federal de São Carlos,

\section{Resumo}

0 objetivo do estudo foi investigar os efeitos da dieta hiperlipídica e do treinamento de natação e força sobre o tecido adiposo, perfil lipídico e sistema endocanabinóide de ratos obesos exógenos. Para isso, utilizamos sessenta ratos adultos machos divididos em seis grupos: Sedentário Padrão (SP); Sedentário Hiperlipídico (SH); Natação Padrão (NP); Natação Hiperlipídica (NH); Força Padrão (FP); Força Hiperlipídica (FH). Após três semanas recebendo dieta padrão ou hiperlipídica, os animais iniciaram os protocolos de exercício. Os grupos NP e NH nadaram 60 minutos/dia, 5 dias/semana com carga de $5 \%$ do peso corporal atada ao corpo, em tanques de $50 \times 30 \mathrm{~cm}$, durante 8 semanas. Os grupos FP e FH realizaram exercício de subida em escada com pesos atados às suas caudas, uma vez a cada três dias, durante 8 semanas. Os animais dos grupos SP e SH continuaram sedentários e alimentados com suas respectivas dietas. A dieta hiperlipídica aumentou o ganho de massa corporal, peso relativo dos tecidos adiposos (epididimal, retroperitoneal, visceral e subcutâneo) e área de adipócitos (epididimal, retroperitoneal e visceral). Também aumentou o percentual de gordura de todos os tecidos adiposos e fígado, além de aumentar a expressão gênica do receptor CB1. Os grupos treinados apresentaram menores valores de área de adipócitos, melhora do perfil lipídico, menores valores no percentual de gordura dos tecidos adiposos e fígado, menores ganhos de massa corporal, além de menores expressão gênica do receptor CB1. Assim nossos resultados indicam os potenciais benefícios do treinamento força e natação, como alternativas não farmacológicas para controlar os efeitos deletérios da dieta hiperlipídica sobre o tecido adiposo, perfil lipídico, conteúdo lipídico e controle do desequilíbrio do sistema endocanabinóide provocado pela dieta hiperlipídica.

Palavras-chave: Obesidade; Treinamento de força; Natação; Receptor CB1; Sistema endocanabinóide.

\section{Introdução}

A obesidade tem se tornado uma pandemia, principalmente em países industrializados. Perigosamente e de maneira concomitante com o aumento desenfreado no número dos casos de obesidade, ocorre o aumento da prevalência de suas co-morbidades tais como doenças cardiovasculares, diabetes tipo 2, hipertensão, hiperlipidemia, esteatose hepática não alcoólica, acidente vascular cerebral além de algumas formas de cânceres. Neste sentido, o tecido adiposo é mais do que simplesmente um órgáo de armazenamento de excesso de energia. É responsável por processos metabólicos complexos 
além de secretar substâncias que se interagem com outras partes do corpo influenciando vários sistemas, incluindo a ingestáo de alimentos e o metabolismo energético ${ }^{1}$.

A regulaçáo do balanço energético consiste em uma complexa rede de sistemas de feedback, envolvendo controle hormonal e neural da energia ingerida e da energia gasta. Assim, o desequilíbrio energético leva a mudanças bruscas no metabolismo dos adipócitos ${ }^{2,3}$. Da mesma forma o Sistema Endocanabinóide (SE), descoberto na década de 90, é também um sistema de sinalização que controla o comportamento alimentar e que, na obesidade, parece estar hiperativo ${ }^{4}$. Ele pode acentuar ou diminuir o desejo de consumir alimentos (interagindo com o mecanismo de recompensa), modular os mediadores orexígenos ou anorexígenos e induzir o apetite após períodos de jejum $^{4}$, desempenhando papel chave na regulação da homeostase energética ${ }^{2}$. Portanto tem sido sugerido que este sistema integra a ingestão de nutrientes, o metabolismo e o armazenamento energético, mantendo o equilíbrio homeostático.

Vale ressaltar que o sistema endocanabinóide é constituído pelos receptores canabinóides CB1 e CB2, substâncias canabinóides agonistas e antagonistas, e enzimas que catalisam sua síntese e degradação. Possui açóes neuromodulatórias, por influenciar a atividade de outros sistemas neurotransmissores. No entanto, ao contrário dos neurotransmissores clássicos os endocanabinóides são sintetizados sob demanda em resposta a estimulação aguda ${ }^{3}$.

A função principal dos endocanabinóides é restaurar a homeostase em locais que tenham sofrido algum tipo de desequilíbrio devido a condiçôes patológicas ou de estresse, como por exemplo, jejum, atividade neural intensa, danos celulares, atividade intensa dos receptores de citocinas inflamatórias e obesidade, dentre outras ${ }^{3}$. Portanto, a desregulação do SE, que se manifesta como hiperatividade do sistema, parece ter relação crítica entre a obesidade, principalmente a visceral e suas co-morbidades ${ }^{5,6}$. Por exemplo, os endocanabinoides plasmáticos são elevados em indivíduos com obesidade e em pacientes com diabetes tipo $2^{6-7}$. Em um estudo com ratos knockout para o receptor CB1, mostrou que estes são resistentes à obesidade induzida por dieta rica em gordura, sugerindo que a hiperativaçáo do $S E$ pode desempenhar um papel no desenvolvimento ou manutenção da obesidade além de um suporte adicional de um potencial benefício do bloqueio de CB1 de ação periférica sobre alterações metabólicas ${ }^{1}$.

Um forte indício do envolvimento do SE e os receptores $\mathrm{CB} 1$ na modulação do apetite e ingestão alimentar, veio da observação de que compostos antagônicos ao CB1 são capazes de influenciar negativamente o aumento da ingestâo de sacarose induzida pelo neuropeptídeo Y (NPY) (gene orexígeno) $^{8}$. Além disso, a ativação do CB1 também aumenta a formação de adipócitos (via enzimas lipogênicas) ${ }^{6,9,10}$ sendo que os processos de adipogênese e lipogênese são altamente controlados por fatores de transcrição, pertencente à família de receptores nucleares, como o receptor ativado por proliferadores de peroxissomas gama $(\operatorname{PPAR} \gamma)^{11}$. O PPAR $\gamma$ regula a homeostase da glicose e metabolismo dos lipídeos, influenciando na diferenciação dos adipócitos e regulando o acúmulo de lipídios. Sua ativação induz o acúmulo de gordura, diferenciação celular lipídica e aumenta a sensibilidade à insulina ${ }^{12,13}$. Esse papel justifica a importância da análise tanto da sua atividade quanto de sua expressão, principalmente na obesidade.

Deste modo, há grande interesse por parte da sociedade científica em investigar estratégias para prevenir ou atenuar os efeitos deletérios da obesidade. Em alguns casos, modificaçóes de estilo de vida, com melhora na qualidade nutricional da dieta e aumento na prática de atividade física, provaram ser benéfico em controlar a obesidade ${ }^{14}$. É sabido que a atividade física retarda a progressão da síndrome metabólica, previne o desenvolvimento de doenças coronarianas, aumenta a sensibilidade à insulina e melhora o perfil de risco metabólico14. Estudos têm mostrado que o treinamento de força também pode ser uma ferramenta eficiente na redução dos depósitos de tecido adiposo ${ }^{15-17}$.

Com relação ao SE e o exercício, GomEs DA SiLva e colaboradores ${ }^{18}$, mostraram que um programa de exercício aeróbio realizado durante a adolescência de ratos, reduziu significativamente a expressão de receptores CB1 no hipocampo. Em estudo de YAN et al. ${ }^{19}$, envolvendo dieta hiperlipídica, exercício e expressão de receptores $\mathrm{CB} 1$, os animais tiveram a expressão de CB1 no tecido adiposo visceral e subcutâneo reduzida em $33 \%$ e $71 \%$, respectivamente. Hipotetizamos neste estudo que a dieta hiperlipídica leva ao desenvolvimento da obesidade através do aumento dos tecidos adiposos, dislipidemias e superestimulação do sistema endocanabinóide. E que os protocolos de treinamento (força e natação) são capazes de 
prevenir os efeitos deletérios deste tipo de dieta, promovendo mudanças no perfil lipídico, tecidos adiposos, fígado e receptores CB1. Portanto, objetivo do presente estudo foi investigar os

\section{Método}

\section{Animais e Condiçóes Experimentais}

Foram utilizados 60 ratos machos da Linhagem Wistar, com 90 dias de idade, provenientes do Biotério Central da Universidade Federal de São Carlos (UFSCar). Os animais foram mantidos em gaiolas individuais e permaneceram no Biotério do Laboratório de Nutriçáo e Metabolismo Aplicados ao Exercício-Departamento de Educação Física e Motricidade Humana/UFSCar, com temperatura ambiente entre 22 e $24^{\circ} \mathrm{C}$ e luz controlada em ciclo de $12 \mathrm{~h}$ (claro/escuro). A água e a comida foram administradas ad libitum. Antes de iniciar as intervençôes experimentais, os animais permaneceram durante uma semana em condiçóes de aclimataçẫo recebendo dieta padrão ad libitum. $\mathrm{O}$ experimento foi conduzido segundo as normas internacionais de ética em experimentação animal. Todos os procedimentos foram aprovados pelo Comitê de Ética em Experimentação Animal da UFSCar (Protocolo no 032/2009).

\section{Composição das dietas}

Foram utilizados dois tipos diferente de dieta, descritas a seguir:

1) Dieta Padrão: raçáo balanceada para roedores (em forma de pellets) fornecida por Primor (São Paulo, Brasil). Cada $100 \mathrm{~g}$ da dieta contem $23 \%$ de proteína, $49 \%$ de carboidratos, $4 \%$ de gordura total, $5 \%$ de fibra, $7 \%$ de cinza, e $6 \%$ de vitaminas, conforme fornecido pelo fabricante.

2) Dieta hiperlipídica: ração balanceada para roedores fornecida por Primor (Sáo Paulo, Brasil), amendoim torrado, chocolate com leite (em $100 \mathrm{~g}: 18 \mathrm{~g}$ de carboidratos, $1 \mathrm{~g}$ de proteína, $10 \mathrm{~g}$ de gordura total e $1 \mathrm{~g}$ de fibra, fornecida por Harald Industria e Comércio de Alimentos LTDA., São Paulo- SP, Brasil) e bolacha maisena (em $100 \mathrm{~g}: 23 \mathrm{~g}$ de carboidratos, 2,7 g de proteína, $3,5 \mathrm{~g}$ de gordura total e $0 \mathrm{~g}$ de fibra efeitos da dieta hiperlipídica e do treinamento de natação e força sobre o tecido adiposo, perfil lipídico e sistema endocanabinóide de ratos obesos exógenos.

produzida pela Cipa Industrial de Produtos Alimentares Ltda. Aparecida de Goiânia-GO, Brasil). Todos os componentes foram moídos e misturados na proporção de 3: 2: 2: 1 . Cada $100 \mathrm{~g}$ de $\mathrm{H}$ continha $20 \%$ de proteína, $20 \%$ de gordura, $48 \%$ de carboidrato e $4 \%$ de fibra.

A densidade calórica das dietas foi determinada por meio de um calorímetro adiabático (IKAC400) sendo de $5,12 \mathrm{kcal} / \mathrm{g}$ para dieta hiperlipídica e 4,07 kcal/g para dieta padrão ${ }^{22}$.

\section{Grupos experimentais}

Após período de aclimatação, os animais foram divididos em 6 grupos ( $\mathrm{n}=10$ por grupo) de acordo com a dieta e tipo de intervenção. São eles: Sedentário e dieta padrão (SP); Sedentário e dieta hiperlipídica (SH; Natação e dieta padrão (NP; Natação e dieta hiperlipídica $(\mathrm{NH})$; Força e dieta Padrão (FP); Força e dieta hiperlipídica $(\mathrm{FH})$. Os grupos sedentários permaneceram sem nenhum tipo de exercício durante todo o período experimental. Os grupos treinados foram submetidos aos respectivos treinamentos durante 8 semanas. O desenho experimental está representado na FIGURA 1.

\section{Protocolos de exercício}

\section{Natação}

Os animais passaram por uma semana de adaptaçấo, começando o treinamento com duração de 30 minutos, progredindo diariamente até alcançarem $60 \mathrm{~min} / \mathrm{dia}$. O treinamento foi realizado com uma frequência de 05 vezes por semana, durante 60 minutos/dia, por um período de 8 semanas com 5\% do peso corporal atado ao corpo $^{21}$. Os animais nadaram em tanques individuais de $50 \mathrm{~cm}$ de altura por $30 \mathrm{~cm}$ de diâmetro, sendo a temperatura da água mantida entre $30-34^{\circ} \mathrm{C}$ e trocada diariamente. 
FIGURA 1 - Desenho experimental.

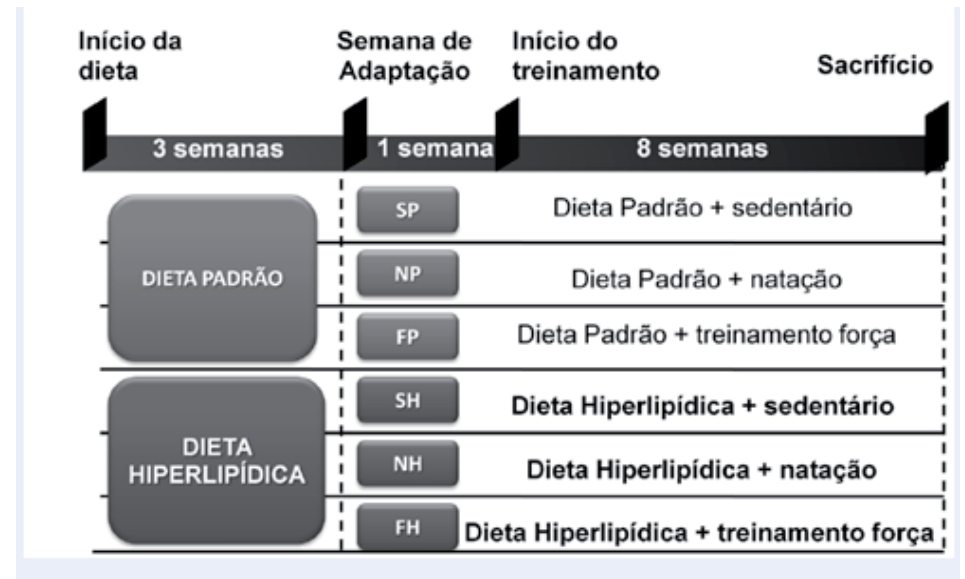

\section{Treinamento de força}

Após três semanas alimentados com dietas padrão e hiperlipídica, os grupos FP e FH iniciaram o treinamento de força. O protocolo de Hornerberg e Farrar (2004)22 foi adaptado para as necessidades e execução da pesquisa. Inicialmente os ratos foram familiarizados com o treinamento de força que consiste em subidas em uma escada $(1,1 \times 0,18 \mathrm{~m}$, 2 -cm espaçamento entre os degraus da grade, $80^{\circ}$ de inclinação) com uma carga de aparatos fixados em sua cauda (FIGURA 2).

FIGURA 2 - Treinamento de Escada.

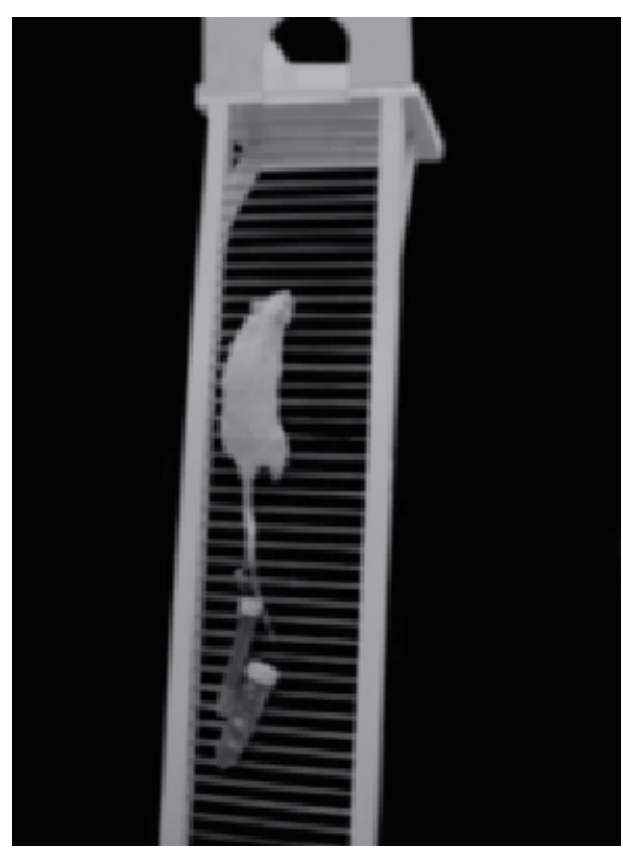

Devido ao tamanho da escada os animais realizavam de 8 a 12 movimentos por escalada. $\mathrm{O}$ aparato fixado na cauda consistiu em frascos cônicos plásticos com pesos de chumbo, presos a uma fita adesiva. Os ratos foram colocados na parte inferior da escada e adaptados com o ato de escalar. 
Inicialmente, foram motivados a escalar aplicandose em sua cauda um estímulo manual para iniciar o movimento. No topo da escada, encontra-se uma gaiola $(20 \times 20 \times 20 \mathrm{~cm})$ onde o animal descansou por 120 segundos entre as séries. Este procedimento foi repetido até que os ratos voluntariamente subissem a escada três vezes consecutivas, sem o incentivo na cauda. Três dias seguintes à familiarização com a escada (dois dias de descanso e no terceiro dia de treinamento novamente), os grupos experimentais iniciaram o treinamento de força. A primeira sessão de treinamento consistiu em escalar de quatro a oito escadas carregando progressivamente cargas mais pesadas. $\mathrm{Na}$ escalada inicial foi aplicado $75 \%$ do peso do corpo do animal. Após completar o carregamento desta carga com sucesso, um peso adicional de 30 gramas foi adicionado ao aparato. Este procedimento foi sucessivamente repetido até que a carga alcance um peso que não permita que o rato consiga escalar. Então, a maior carga carregada com sucesso até o topo da escada foi considerada a carga máxima dos ratos para aquela sessão. As sessóes de treinos subsequentes consistiram de quatro a nove escaladas. Durante as primeiras quatro escaladas, os ratos carregaram $50 \%, 75 \%, 90 \%$ e $100 \%$ de suas cargas máximas. Para as próximas escaladas, foi acrescido 30 gramas para cada escalada até que o rato obtivesse uma nova capacidade máxima de carregamento. Este treinamento foi repetido uma vez a cada três dias, (descanso de dois dias e no terceiro dia uma nova sessão de treinamento) ${ }^{22}$.

\section{Massa corporal, Consumo alimentar e Eficiência Alimentar}

A massa corporal e o consumo alimentar foram controlados diariamente.

O consumo alimentar foi calculado pela diferença de peso entre a ração ofertada e a sobra desta ração:

Consumo Alimentar $(\mathrm{g})$ = ração ofertada - sobra da ração ofertada

A eficiência alimentar foi calculada pela equação abaixo:

Eficiência alimentar $(\%)=$ Ganho de massa corporal (g)/ consumo alimentar total (g) x100

\section{Coleta dos Tecidos}

Os animais foram sacrificados por decapitação em guilhotina. Os animais treinados foram sacrificados 48 horas após a última sessão de exercício. Após a decapitação, o os tecidos adiposos retroperitoneal, epididimal, visceral e subcutâneo e o fígado foram coletados, pesados e imediatamente congelados em nitrogênio líquido e entâo armazenados em freezer $-80^{\circ} \mathrm{C}$ para posterior análise. O sangue foi coletado, centrifugado e armazenado a $4^{\circ} \mathrm{C}$.

\section{Parâmetros lipídicos}

O plasma foi separado em alíquotas para as análises de concentração de colesterol total, lipoproteína de alta densidade (HDL) e triacilgliceróis. As determinaçóes bioquímicas foram obtidas por métodos enzimáticos colorimétricos com Kits específicos da marca Laborlab (Guarulhos, São Paulo - Brazil). A mensuração foi feita em espectrofotômetro ultravioleta (modelo SP-220, Biospectro, Brasil).

\section{Determinaçáo da área de adipócitos}

Aproximadamente 100mg dos tecidos adiposos retroperitoneal (RET), epididimal (EPI) e visceral (VIS) foram removidos de cada depósito de gordura e colocados em solução salina, de forma a lavar e remover as gorduras livres. Em seguida, para a determinação do tamanho das células adiposas, os tecidos foram fixados em tampáo colidina $0,2 \mathrm{M}$, contendo $1 \%$ de tetróxido de ósmio, em estufa a $37^{\circ} \mathrm{C}$, por um período de 24 horas. As células foram lavadas e suspensas em solução salina morna e imediatamente espalhadas em lâminas ${ }^{23}$. A área de adipócitos foi mensurada usando o software de análise de imagem (Image Pro Plus, KS- $300^{\circ}$, da Carl Zeiss) e expressa como $\mu \mathrm{m} 2$.

\section{Determinaçáo do conteúdo lipídico dos tecidos}

Foi usado um grama dos tecidos adiposos epididimal, retroperitoneal, visceral e subcutâneo e também do fígado. Os tecidos foram colocados em tubos contendo $3 \mathrm{ml}$ de hidróxido de potássio $30 \%$ os quais foram aquecidos em banho-maria a $70^{\circ} \mathrm{C}$ por 15 minutos para digestão e saponificação. Em seguida, foi adicionado $3 \mathrm{ml}$ de etanol absoluto permanecendo os tubos em banho-maria a $70^{\circ} \mathrm{C}$ por mais 1 hora e 45 minutos, para a total hidrólise dos triglicerídeos, ésteres de colesterol e fosfolipídios. Posteriormente, os tubos foram resfriados e foi adicionado $2,5 \mathrm{ml}$ de ácido sulfúrico $6 \mathrm{~N}$ à mistura 
saponificada. Conforme método descrito por STANSBIE et al. ${ }^{24}$, os ácidos graxos totais e o colesterol livre foram extraídos por 3 lavagens sucessivas com éter de petróleo ( $8 \mathrm{ml}, 6 \mathrm{ml} \mathrm{e} 4 \mathrm{ml}$ respectivamente). O produto das extraçóes foi lavado com $2 \mathrm{ml}$ de água destilada e em seguida transferido para frascos, os quais foram previamente pesados (peso inicial do frasco), e permaneceram em capela a temperatura ambiente até a total evaporaçáo do éter de petróleo, sendo o frasco novamente pesado (peso final do frasco). O Percentual de Gordura dos Tecidos foi determinado através da seguinte equação:

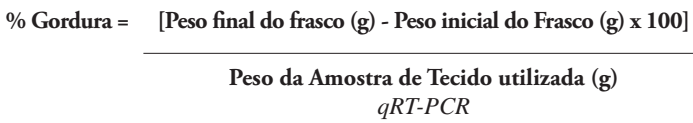

Amostras congeladas de tecido adiposo visceral (100 $\mathrm{mg}$ ) foram homogeneizadas usando o reagente de Trizol $^{\bullet}$ (Invitrogen Corporation, Califórnia, EUA) de acordo com as instruçôes do fabricante, para extração do RNA total. A pureza e o rendimento do RNA total foram determinados medindo a absorvência (densidade óptica no NanoDrop) de alíquotas a 260 e $280 \mathrm{~nm}$ (proporçóes: $260 \mathrm{~nm} / 280 \mathrm{~nm}$ e 230/280). A integridade do RNA foi visualizada com brometo de etidio em $2 \%$ de gel de agarose, por eletroforese com um padráo de RNA ribossômico $28 \mathrm{~S}$ e 18S. Cada amostra de RNA total (1 lg) foi tratada com DNase I- Deoxyribonuclease I, Amplification Grade (Invitrogen Corporation Califórnia, EUA) para remover contaminantes de DNA genômico. $\mathrm{O}$ cDNA foi sintetizado por transcrição reversa usando transcriptase reversa M-MLV (Promega

\section{Resultados}

\section{Ganho de massa corporal}

Nas 3 primeiras semanas do experimento, nas quais os grupos receberam suas respectivas dietas, os animais que receberam a dieta hiperlipídica apresentaram maiores valores de massa corporal em relação aos animais que receberam dieta padrão, com $\mathrm{p}<0,01$ (FIGURA 3A). Após a segunda fase do experimento todos os grupos alimentados com dieta hiperlipídica
Corporation, Madison, WI, EUA). Para qRT-PCR em tempo real (Rotor Gene, R 3000 (Robertt Research), 20 ng de cDNA e $0,5 \mu \mathrm{L}$ de cada primer foi utilizado em um mix de volume de $25 \mu \mathrm{L}$ contendo SYBR Green PCR (Promega Corporation, Madison, WI EUA). As sequências de dos primers utilizados neste estudo foram as seguintes: CB1-(Fwd: 5-TGGAAGGCTCACAGCCACGC-3, Rev: 5-GCTTGGTCAGGCCGGGTCAC-3), PPAR $\gamma 2$ (Fwd: 5-AAGGGGCCTGGACCTCTGCTG-3, Rev: 5-G ATAAGGCGGGGACGCAGGCT-3). Os resultados foram normalizados para o gene housekeeping GAPDH (Fwd: 5-GGTGGAGAGCACCAAGACAGA-3, Rev: 5-GCCGGAGTCGACAATGATG-3). Os primers estão disponíveis no site do NCBI: CB1 (NM_012784.4); PPAR 2 (NM_001145366.1); GAPDH (NM_017008.3).

\section{Análise estatística}

A análise estatística foi realizada pelo teste de normalidade Kolmogorov-Smirnov e pelo teste de homocedasticidade (critério de Barlet). Foi utilizada Anova-two-way para comparar as variáveis, levando-se em consideraçẫo dois fatores intervenientes (exercício e dieta). Anova oneway e teste-t para variáveis independentes foram utilizados quando necessários. Todos os dados foram apresentados como média \pm erro padrão da média. Também foi aplicado o teste post-hoc de Fisher nos eventos de $\mathrm{F}$ ratio significante $(\mathrm{p}<0.05)$. Todos os procedimentos estatísticos foram realizados pelo programa estatístico Statistica 6.1 (Tulsa, OK, USA). apresentaram valores maiores em relação aos grupos que foram alimentados com dieta padrão $(\mathrm{p}<0,01)$. Comparando os grupos sedentários e treinados, os grupos que realizaram treinamento em natação (NP e NH) exibiram valores menores no ganho de massa corporal com $\mathrm{p}=0,003 \mathrm{e}$ $\mathrm{p}<0,001$, respectivamente. Entre os grupos treinados, tanto o grupo FP quanto FH tiveram maior ganho de massa corporal que os grupos que nadaram ( $\mathrm{p}=0,03$ e $\mathrm{p}=0,01)$ (FIGURA 3B). 
FIGURA 3 - Massa corporal. A) Ganho de massa corporal nas 3 primeiras semanas de dieta. Todos os valores estão descritos como média \pm erro padrão. $\mathrm{p} \leq 0.05$. B) Ganho de massa corporal nas 9 semanas de dieta e treinamento. Todos os valores estão descritos como média \pm erro padrão; a $\mathrm{p} \leq 0.05$ comparando grupos alimentados de dieta padrão x dieta hiperlipídica em seus respectivos grupos; b p $\leq 0.05$ comparando sedentários x treinados; c p $\leq 0.05$ comparando natação x treinamento de força.

A)

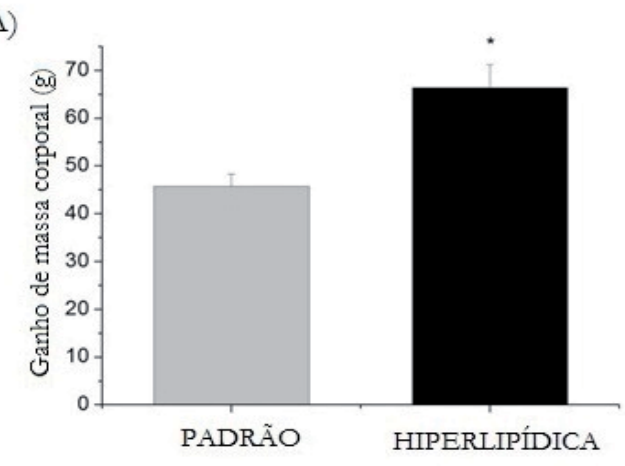

SP: Sedentário Padrão; SH: Sedentário Hiperlipídico;

NP: Treinado Natação Padrão;

NH: Treinado Natação Hiperlipídica;

FP: Treinado Força Padrão;

FH: Treinado Força Hiperlipídica.

Todos os valores estão descritos como média \pm erro padrão; ${ }^{a} p \leq 0.05$ comparando grupos alimentados de dieta padrão $x$ dieta

B)

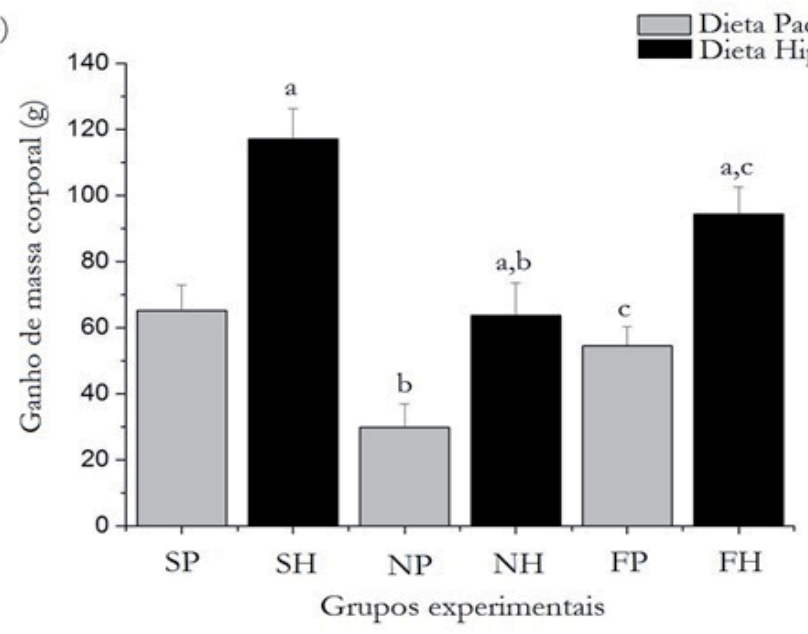

hiperlipídica em seus respectivos grupos;

${ }^{b} p \leq 0.05$ comparando sedentários $\mathrm{x}$ treinados: ${ }^{c} p \leq 0.05$ comparando natação $\mathrm{x}$ treinamento de força.

SP: Sedentário Padrão; SH: Sedentário Hiperlipídico;

NP: Treinado Natação Padrão;

$\mathrm{NH}$ : Treinado Natação Hiperlipídica;

FP: Treinado Força Padrão;

FH: Treinado Força Hiperlipídica.

\section{Consumo Alimentar, Ingestáo Calórica e Eficiência Alimentar (EA)}

Não houve diferenças estatísticas em relação ao consumo alimentar quando comparados os grupos sedentários ( $\mathrm{SP}$ e SH) $(\mathrm{p}=0,34)$ (TABELA 1). Já os grupos alimentados com dieta hiperlipídica e que realizaram exercício $(\mathrm{NH}$ e $\mathrm{FH}$ ) apresentaram menor consumo alimentar quando comparados aos grupos alimentados com dieta padráo e exercício (NP e FP) $(\mathrm{p}<0,05)$ respectivamente, bem como quando comparados ao grupo $\mathrm{SH}(\mathrm{p}<0,05)$. O grupo $\mathrm{NH}$ apresentou maior consumo alimentar que o grupo FH $(p=0,002)$. Os grupos alimentados com dieta hiperlipídica (SH, NH e FH) apresentaram maior ingestão calórica do que os grupos alimentados com dieta padrão (SP, NP e FP). Os grupos $\mathrm{NH}$ e $\mathrm{FH}$ apresentaram menor ingestão calórica quando comparados com o grupo $\mathrm{SH}(\mathrm{p}=0,01 ; \mathrm{p}<0,001)$.

Nas 3 primeiras semanas do experimento, a Eficiência Alimentar (EA) dos animais que receberam dieta hiperlipídica foi significativamente maior do que os animais que receberam dieta padrão $(\mathrm{p}<0,001)$ (FIGURA 4A). A E.A. após 9 semanas todos os grupos alimentados com dieta hiperlipídica exibiram valores maiores que os grupos alimentados com dieta padrão $(\mathrm{p}<0,001)$. Os grupos que nadaram apresentaram menor E.A. que os grupos sedentários e treinados em força $(\mathrm{p}<0,001)$ (FIGURA 4A). 
TABELA 1 - Efeitos do exercício e da dieta no consumo alimentar e ingestão calórica.

Todos os valores estão descritos como média \pm erro padrão a $p \leq 0.05$ comparando grupos alimentados de dieta padrão $\mathrm{x}$ dieta hiperlipídica;

${ }^{b} p \leq 0.05$ comparando sedentários $x$ treinados ${ }^{c} p \leq 0.05$ comparando natação $x$ treinamento de força.

SP: Sedentário Padrão; SH: Sedentário Hiperlipídico;

NP: Treinado Natação Padrão;

NH: Treinado Natação Hiperlipídica;

FP: Treinado Força

Padrão;

FH: Treinado Força

Hiperlipídica.

SP: Sedentário Padrão;

SH: Sedentário

Hiperlipídico;

NP: Treinado Natação

Padrão;

$\mathrm{NH}$ : Todos os valores

estão descritos como

média \pm erro padrão;

a $p \leq 0.05$ comparando

grupos alimentados

de dieta padrão $\mathrm{x}$ dieta

hiperlipídica;

${ }^{b} p \leq 0.05$ comparando

sedentários $\mathrm{x}$ treinados

${ }^{c} p \leq 0.05$ comparando

natação $x$ treinamento

de força.

SP: Sedentário Padrão

SH: Sedentário

Hiperlipídico;

NP: Treinado Natação

Padrão;

$\mathrm{NH}$ : Treinado Natação

Hiperlipídica;

FP: Treinado Força

Padrão;

FH: Treinado Força

Hiperlipídica.

\begin{tabular}{lcc}
\hline & Consumo alimentar $(\mathbf{g})$ & Ingestáo calórica (Kcal) \\
\hline SP & $2348,20 \pm 74,78$ & $9557,17 \pm 304,37$ \\
SH & $2260 \pm 69,70$ & $11571,2 \pm 357,30^{\mathrm{a}}$ \\
$\mathrm{NP}$ & $2301 \pm 63,36$ & $9368,73 \pm 257,89$ \\
$\mathrm{NH}$ & $2041,77 \pm 61,79^{\mathrm{a}, \mathrm{b}}$ & $10453,90 \pm 316,38^{\mathrm{a}, \mathrm{b}}$ \\
$\mathrm{FP}$ & $2232,40 \pm 55,61$ & $9085,86 \pm 226,37$ \\
$\mathrm{FH}$ & $1961,22 \pm 63,49^{\mathrm{a}, \mathrm{b}, \mathrm{c}}$ & $10041,15 \pm 325,08^{\mathrm{a}, \mathrm{b}}$ \\
\hline
\end{tabular}

FIGURA 4 - Eficiência Alimentar. Figura 4: Eficiência Alimentar. A) Eficiência alimentar nas 3 semanas de dieta. Todos os valores estão descritos como média \pm erro padrão. $\mathrm{p} \leq 0.05 . \mathrm{B}$ ) Eficiência alimentar nas 9 semanas de dieta e treinamento. Todos os valores estão descritos como média \pm erro padrão; a $p$ $\leq 0.05$ comparando grupos alimentados de dieta padrão $\mathrm{x}$ dieta hiperlipídica; b p $\leq 0.05$ comparando sedentários $\mathrm{x}$ treinados; c $\mathrm{p} \leq 0.05$ comparando natação $\mathrm{x}$ treinamento de força.

A)

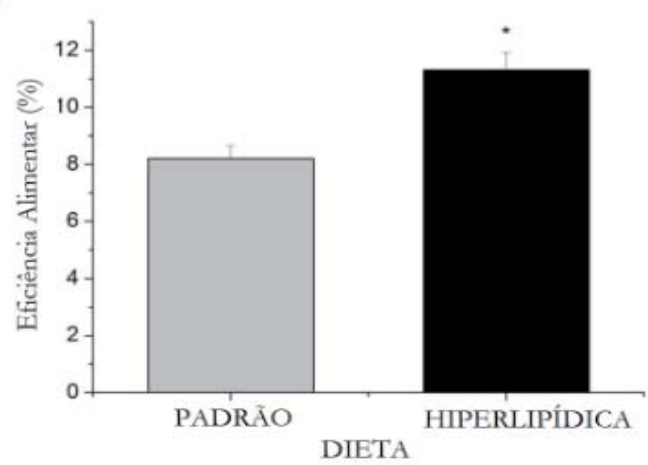

B)

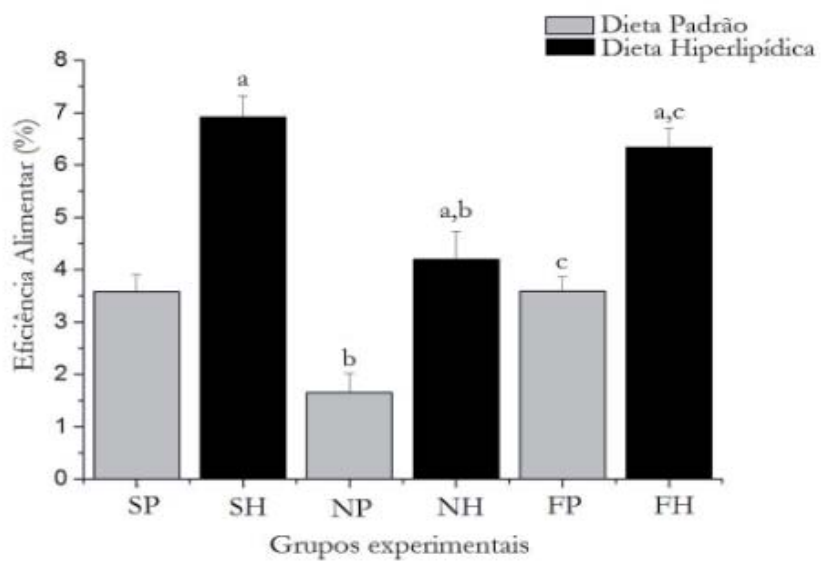

166 • Rev Bras Educ Fís Esporte, (São Paulo) 2021 Jan-Mar;35(1):159-175 


\section{Peso Relativo dos Tecidos}

Os grupos alimentados com dieta hiperlipídica apresentaram maiores pesos relativos dos tecidos adiposos epididimal, retroperitoneal, visceral e subcutâneo quando comparados aos grupos alimentados com dieta padrão $(\mathrm{p}<0,05)$ (TABELA 2). O peso relativo do tecido epididimal foi menor nos grupos $\mathrm{NH}$ $(\mathrm{p}=0,03)$ e $\mathrm{FH}(\mathrm{p}=0,04)$ do que o grupo $\mathrm{SH}$. Também o grupo NP mostrou valores menores de peso relativo do tecido adiposo epididimal que o grupo $S P(p=0,03)$. No entanto, o grupo $\mathrm{NH}$ exibiu maiores valores de peso relativo do tecido adiposo visceral que os grupos $\mathrm{SH}(\mathrm{p}=0,009)$ e FH $(\mathrm{p}<0,001)$.

TABELA 2 - Efeitos do exercício e da dieta no peso relativo dos tecidos.

\begin{tabular}{lcccccc}
\hline & EPI $(\mathbf{g})$ & RET $(\mathbf{g})$ & VIS $(\mathbf{g})$ & SUB $(\mathbf{g})$ & TAM $(\mathbf{g})$ & FÍGADO $(\mathbf{g})$ \\
\hline SP & $1,32 \pm 0,11$ & $1,21 \pm 0,11$ & $0,88 \pm 0,05$ & $0,68 \pm 0,11$ & $0,0007 \pm 0,00005$ & $0,0273 \pm 0,0009$ \\
SH & $2,63 \pm 0,22^{\mathrm{a}}$ & $2,47 \pm 0,19^{\mathrm{a}}$ & $1,86 \pm 0,19^{\mathrm{a}}$ & $1,02 \pm 0,09^{\mathrm{a}}$ & $0,0009 \pm 0,00005^{\mathrm{a}}$ & $0,0271 \pm 0,0009^{\mathrm{a}}$ \\
$\mathrm{NP}$ & $0,85 \pm 0,07^{\mathrm{b}}$ & $0,72 \pm 0,06$ & $0,80 \pm 0,05$ & $0,68 \pm 0,05$ & $0,0018 \pm 0,00012^{\mathrm{b}}$ & $0,0284 \pm 0,0006$ \\
NH & $2,16 \pm 0,18^{\mathrm{a}, \mathrm{b}}$ & $2,66 \pm 0,29^{\mathrm{a}}$ & $2,42 \pm 0,21^{\mathrm{a}, \mathrm{b}}$ & $1,19 \pm 0,12^{\mathrm{a}}$ & $0,0020 \pm 0,00015^{\mathrm{b}}$ & $0,0254 \pm 0,0006^{\mathrm{a}}$ \\
FP & $1,18 \pm 0,10$ & $1,13 \pm 0,10$ & $0,84 \pm 0,07$ & $0,81 \pm 0,04$ & $0,0008 \pm 0,00004^{\mathrm{c}}$ & $0,0252 \pm 0,0006^{\mathrm{c}}$ \\
FH & $2,18 \pm 0,17^{\mathrm{a}, \mathrm{b}}$ & $2,36 \pm 0,18^{\mathrm{a}}$ & $1,61 \pm 0,18^{\mathrm{a}, \mathrm{c}}$ & $1,26 \pm 0,08^{\mathrm{a}}$ & $0,0010 \pm 0,00009^{\mathrm{c}}$ & $0,0244 \pm 0,0006^{\mathrm{b}}$ \\
\hline
\end{tabular}

\section{Área de Adipócitos}

O grupo $\mathrm{SH}$ apresentou médias de área de adipócitos maiores dos tecidos adiposos EPI, RET e VISC quando comparados ao grupo SP $(\mathrm{p}<0,001)$ (TABELA 3). Resultados similares foram observados quando comparamos os grupos de dieta hiperlipídica e exercício com os seus respectivos grupos de dieta padrão e exercício $(\mathrm{p}<0,001)$. Além disso, os grupos treinados em natação apresentaram menores valores de áreas de adipócitos, em todos os tecidos, quando comparados aos grupos sedentários $(\mathrm{p}<0,001)$, com exceção da área de adipócitos do tecido adiposo visceral no grupo $\mathrm{NH}$. Já o grupo $\mathrm{FH}$ mostrou valores maiores de área de adipócitos quando comparados ao grupo FP $(\mathrm{p}<0,005)$. Com exceção das áreas dos tecidos RET e VISC do grupo FH, os valores das áreas de todos os outros tecidos foram menores nos grupos sedentários (SP e SH) e treinados em natação (NP e NH) do que nos grupos treinados em força (FP e FH; $\mathrm{p}<0,001)$.

TABELA 3 - Área de adipócitos dos tecidos epididimal, retroperitoneal e visceral.

\begin{tabular}{|c|c|c|c|}
\hline SP & $8843,79 \pm 116,45$ & $14907,79 \pm 164,76$ & $6866,48 \pm 96,17$ \\
\hline $\mathrm{SH}$ & $21920,38 \pm 211,39^{a}$ & $29939,00 \pm 158,12^{a}$ & $12524,88 \pm 153,70^{a}$ \\
\hline $\mathrm{NP}$ & $8440,04 \pm 97,37^{b}$ & $11408,12 \pm 134,66^{\mathrm{b}}$ & $6147,76 \pm 96,28^{b}$ \\
\hline $\mathrm{NH}$ & $21197,49 \pm 282,10^{\mathrm{a}, \mathrm{b}}$ & $28666,48 \pm 272,03^{\mathrm{a}, \mathrm{b}}$ & $16618,87 \pm 264,00^{\mathrm{a}, \mathrm{b}}$ \\
\hline FP & $15436,38 \pm 160,00^{b, c}$ & $18408,13 \pm 136,27^{\mathrm{b}, \mathrm{c}}$ & $8597,10 \pm 120,75^{b, c}$ \\
\hline
\end{tabular}

Peso relativo de tecido adiposo ( $\mathrm{g} / 100 \mathrm{~g}$ de massa corporal). Todos os valores estão descritos como média \pm erro padrão a $p \leq 0,05$ comparando grupos alimentados com dieta padrão $\mathrm{x}$ dieta hiperlipídica; ${ }^{\mathrm{b}} p \leq 0,05$ comparando sedentários $\mathrm{x}$ treinados; ${ }^{c} p \leq 0,05$ comparando natação $x$ treinamento de força ( $n=10$ em cada grupo).

EPI, epididimal; RET, retroperitoneal; VISC visceral;

SUB, subcutâneo; TAM tecido adiposo marrom. SP: Sedentário Padrão; SH: Sedentário Hiperlipídico;

NP: Treinado Natação Padrão;

$\mathrm{NH}$ : Treinado Natação Hiperlipídica; FP: Treinado Força Padrão; FH: Treinado Força Hiperlipídica.

Todos os valores estão descritos como média \pm erro padrão a $p \leq 0.05$ comparando grupos alimentados com dieta padrão x dieta hiperlipidica; ${ }^{b} p \leq 0.05$ comparando sedentários $\mathrm{x}$ treinados ${ }^{c} p \leq 0.05$ comparando natação $x$ treinamento de força $(n=5$ em cada grupo). EPI, epididimal; RET, retroperitoneal; VISC, visceral. SP: Sedentário Padrão; SH: Sedentário Hiperlipídico NP: Treinado Natação Padrão; NH: Treinado Natação Hiperlipídica; FP: Treinado Força Padrão; FH: Treinado Força Hiperlipídica. 
Percentual de gordura dos Tecidos Adiposos e Fígado

Tecido Adiposo Epididimal: Os grupos alimentados com dieta hiperlipídica, com exceção do grupo $\mathrm{FH}$, apresentaram maiores conteúdos lipídicos em relação aos grupos alimentados com dieta padrão $(\mathrm{p}=0,002)$ (TABELA 4). Quando comparados sedentários e treinados, o grupo $\mathrm{FH}$ apresentou valores menores em relação ao seu respectivo grupo $\mathrm{SH}(\mathrm{p}=0,001)$, como também em relaçâo ao grupo $\mathrm{NH}(\mathrm{p}=0,002)$.

Tecido Adiposo Retroperitoneal: Para o tecido adiposo retroperitoneal, apenas o grupo $\mathrm{SH}$ apresentou valores maiores em relação ao grupo SP ( $\mathrm{p}=0,001)$ (TABELA 4). Quando comparamos os sedentários e treinados, os grupos que realizaram treinamento em natação (NP e NH) apresentaram valores menores de conteúdo lipídico quando comparados aos grupos sedentários ( $\mathrm{SP}$ e $\mathrm{SH}$ ), com $\mathrm{p}=0,01$ e $\mathrm{p}<0,001)$ respectivamente, assim como quando comparados com os grupos que treinamento de força (FP e FH), $\mathrm{p}<0,001$.

Tecido Adiposo Visceral: Todos os grupos alimentados com dieta hiperlipídica apresentaram valores maiores de conteúdo lipídico em relação aos grupos alimentados com dieta padráo $(\mathrm{p}<0,01)$ (TABELA 4). Quando comparados os grupos sedentários e treinados, apenas o NP e FP apresentaram valores menores de conteúdo lipídico, em relação ao seu respectivo grupo SP. Entre os grupos treinados, o grupo FP apresentou valores maiores em relação ao grupo NP $(p=0,03)$.

Tecido Adiposo Subcutâneo: Para o tecido adiposo subcutâneo, o grupo $\mathrm{SH}$ apresentou valores maiores em relaçáo ao seu respectivo grupo SP com $p=0,002$. Entre os grupos sedentários e treinados, o grupo $\mathrm{NH}$ apresentou valores de conteúdo lipídico menores quando comparado ao grupo SH ( $\mathrm{p}=0,04)$ (TABELA 4). Não houve diferença no conteúdo lipídico entre os grupos treinados em natação e força para o tecido adiposo subcutâneo.

Fígado: Dos grupos alimentados com dieta hiperlipídica, o SH e FH apresentaram valores maiores de conteúdo lipídico no fígado em relaçáo aos seus respectivos grupos alimentados com dieta padrão, SP $(\mathrm{p}<0,001)$ e FP $(\mathrm{p}=0,02)$ (TABELA 4). Quando comparados os grupos sedentários e treinados, os grupos alimentados com dieta hiperlipídica e exercitados $(\mathrm{NH}$ e $\mathrm{FH})$ apresentaram valores menores de conteúdo lipídico quando comparados ao grupo $\mathrm{SH}$ $(\mathrm{p}<0,001)$. Também náo houve diferença no conteúdo lipídico do fígado entre os grupos treinados em natação e força.
Todos os valores estão descritos como média \pm erro padrão ${ }^{a} p \leq 0.05$ comparando grupos alimentados com dieta padrão $\mathrm{x}$ dieta hiperlipídica;

${ }^{\mathrm{b}} p \leq 0.05$ comparando sedentários $\mathrm{x}$ treinados: ${ }^{c} p \leq 0.05$ comparando natação $x$ treinamento de força $(n=5$ em cada grupo).

EPI, epididimal; RET,

retroperitoneal; $\mathrm{VISC}$

visceral.;

SUB, subcutâneo.

SP: Sedentário Padrão

SH: Sedentário

Hiperlipídico;

NP: Treinado Natação

Padrão;

$\mathrm{NH}$ : Treinado Natação

Hiperlipídica;

FP: Treinado Força

Padrão;

FH: Treinado Força

Hiperlipídica.

TABELA 4 - Conteúdo de Lipídios dos Tecidos Adiposos e Fígado (em \%).

\begin{tabular}{lccccc}
\hline & EPI & RET & VIS & SUB & FÍGADO \\
\hline SP & $1,37 \pm 0,36$ & $15,39 \pm 0,523$ & $56,60 \pm 2,82$ & $14,87 \pm 1,59$ & $1,43 \pm 0,07$ \\
SH & $3,63 \pm 0,59^{\mathrm{a}}$ & $25,40 \pm 1,67^{\mathrm{a}}$ & $65,19 \pm 2,51^{\mathrm{a}}$ & $22,54 \pm 1,52^{\mathrm{a}}$ & $3,70 \pm 0,69^{\mathrm{a}}$ \\
$\mathrm{NP}$ & $1,15 \pm 0,29$ & $7,72 \pm 1,67^{\mathrm{b}}$ & $47,30 \pm 2,57^{\mathrm{b}}$ & $16,91 \pm 1,47$ & $1,61 \pm 0,12$ \\
$\mathrm{NH}$ & $3,44 \pm 0,63^{\mathrm{a}}$ & $8,05 \pm 1,73^{\mathrm{b}}$ & $63,40 \pm 1,63^{\mathrm{a}}$ & $17,34 \pm 1,24^{\mathrm{b}}$ & $1,71 \pm 0,11^{\mathrm{b}}$ \\
FP & $2,49 \pm 0,46$ & $20,49 \pm 2,00^{\mathrm{c}}$ & $54,70 \pm 2,48^{\mathrm{c}}$ & $17,51 \pm 2,86$ & $1,09 \pm 0,09$ \\
FH & $1,22 \pm 0,54^{\mathrm{b}, \mathrm{c}}$ & $22,02 \pm 3,74^{\mathrm{c}}$ & $65,08 \pm 2,54^{\mathrm{a}}$ & $20,76 \pm 1,092$ & $2,04 \pm 0,22^{\mathrm{a}, \mathrm{b}}$ \\
\hline
\end{tabular}

168 • Rev Bras Educ Fís Esporte, (São Paulo) 2021 Jan-Mar;35(1):159-175 


\section{Parâmetros Lipídicos}

Os grupos treinados apresentaram valores menores de colesterol total e TGL e valores maiores de HDL quando comparados aos grupos sedentários $(\mathrm{p}<0,05)$, com exceção do grupo $\mathrm{NH}$, que apresentou maiores valores de TGL quando comparado ao grupo NP $(\mathrm{p}=0,001)$ (TABELA 5). Entre os grupos sedentários, o grupo SH apresentou maiores valores de TGL que o grupo SP $(\mathrm{p}=0,01)$. Além disso, o grupo $\mathrm{NH}$ exibiu maiores valores de colesterol total que o grupo NP $(\mathrm{p}=0,02)$. Quando comparamos os grupos treinados, o grupo NP apresentou menores valores de colesterol total que o grupo FP $(p=0,02)$. Já o grupo $\mathrm{NH}$ mostrou valor de HDL maior que o grupo NP $(p=0,04)$ e FH $(p<0,001)$.

TABELA 5 - Níveis séricos de Colesterol total, HDL e Triacilgliceróis.

Todos os valores estão descritos como média \pm erro padrão. ${ }^{\text {a }} p \leq 0.05$ comparando grupos alimentados com dieta padrão $\mathrm{x}$ dieta hiperlipídica; ${ }^{\mathrm{b}} p \leq 0.05$ comparando sedentários $\mathrm{x}$ treinados ${ }^{c} p \leq 0.05$ comparando natação $\mathrm{x}$ treinamento de força ( $n=10$ em cada grupo);

$\mathrm{HDL}$, lipoproteína de alta densidade; TGL, triacilglicerois. SP: Sedentário Padrão; SH: Sedentário Hiperlipídico; NP: Treinado Natação Padrão;

$\mathrm{NH}$ : Treinado Natação Hiperlipídica; FP: Treinado Força Padrão; FH: Treinado Força Hiperlipídica.

\section{Expressão Gênica de Receptor Canabinóide (CB1) e Receptor Ativado por Proliferadores de Peroxissoma Gama (PPAR $\gamma$ )}

O grupo sedentário e alimentado com dieta hiperlipídica $(\mathrm{SH})$ apresentou maiores valores na expressáo do receptor CB1 comparado ao grupo sedentário e alimentado com dieta padrão $\mathrm{p}=0,001$ (SP) (FIGURA 5A). Quando comparamos os grupos treinados e sedentários, os grupos que realizaram exercício tanto em natação quanto em força apresentaram valores menores que seu respectivo grupo sedentário $(\mathrm{SH})$ com $\mathrm{p}=0,01$. Porém a expressão de PPAR $\gamma$ não houve diferenças significativas entre os grupos (FIGURA 5B). 
FIGURA 5 - Expressão gênica. A) Expressão gênica do receptor canabinóide (CB1). B) Expressão gênica dos Receptor Ativado por Proliferadores de Peroxissoma Gama (PPARY).

Todos os valores estão descritos como média \pm erro padrão a $\mathrm{p} \leq 0.05$ comparando grupos alimentados de dieta padrão $\mathrm{x}$ dieta hiperlipídica;

b $\mathrm{p} \leq 0.05$ comparando sedentários $\mathrm{x}$ treinados $c p \leq 0.05$ comparando natação $x$ treinamento de força ( $n=10$ por grupo)

SP: Sedentário Padrão;

SH: Sedentário Hiperlipídico;

NP: Treinado Natação

Padrão;

$\mathrm{NH}$ : Treinado Natação

Hiperlipídica;

FP: Treinado Força

Padrão;

FH: Treinado Força

Hiperlipídica.
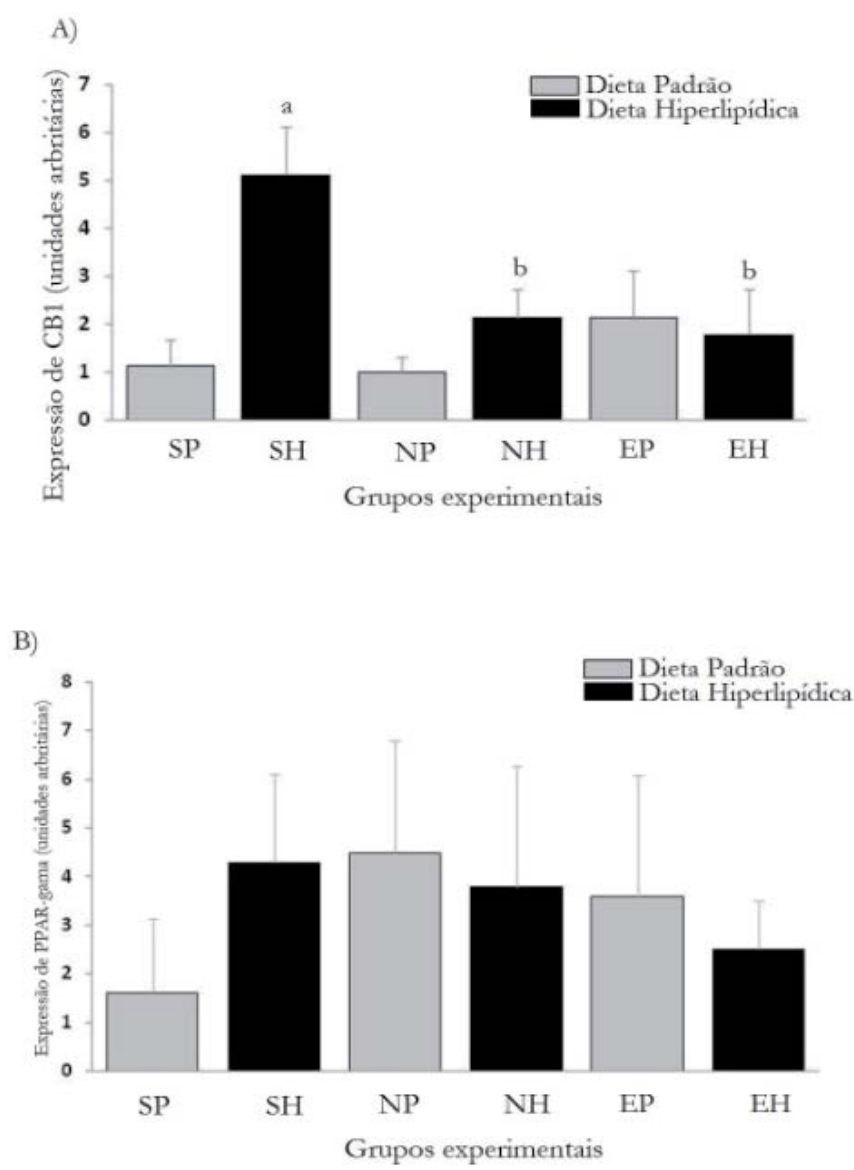

\section{Discussão}

O presente estudo mostrou que tanto o treinamento de natação quanto o treinamento de força foram capazes de prevenir os efeitos deletérios da dieta hiperlipídica em ratos, controlando ganho de massa corporal, melhoras no perfil lipídico e diminuição do conteúdo lipídico dos tecidos, além de ser efetivo em controlar o desequilíbrio do sistema endocanabinóide.

Neste sentido, estudos prévios do nosso grupo de pesquisa demonstraram que apenas 3 semanas de consumo de dieta hiperlipídica foi capaz de aumentar a massa corporal e os depósitos do tecido adiposo, além de promover o desenvolvimento de dislipidemias, em ratos ${ }^{20,21}$. A dieta hiperlipídica possui maior valor calórico $(5,12 \mathrm{kcal} / \mathrm{g})$ em relação a dieta padrão $(4,07 \mathrm{kcal} / \mathrm{g})$, além de aumentar a secreção de colecistoquinina, a qual estimula a liberaçâo de enzimas pancreáticas, responsáveis pelo aumento do tempo de saciedade e consequente reduçáo do consumo alimentar ${ }^{25}$. Além disso, a eficiência alimentar (EA) é um indicador metabólico que mostra o quanto do consumo alimentar foi adicionado ao peso corporal. Assim os maiores valores de EA nos grupos alimentados com dieta hiperlipídica, apesar dos menores valores de consumo alimentar em gramas, correspondem aos maiores ganhos de massa corporal para esses grupos, o que pode explicar nossos resultados. Assim, a associação do gasto energético, devido ao exercício, e o menor consumo alimentar em gramas podem ter contribuído para o menor ganho de massa corporal nos grupos treinados e alimentados com a dieta hiperlipídica quando comparados ao respectivo grupo sedentário.

É conhecido que a dieta hiperlipídica aumenta a 
atividade da lipase lipoprotéica (LPL) no tecido adiposo visceral ${ }^{26}$. A LPL é responsável por hidrolisar TGL das lipoproteínas plasmáticas, principalmente quilomícrons e lipoproteínas de muito baixa densidade (VLDL), em ácidos graxos para posterior deposição nos adipócitos, controlando o armazenamento de lipídeos no tecido adiposo $^{26}$. É provável que isso tenha ocorrido em nosso estudo, já que a área de adipócitos do tecido adiposo visceral e dos outros depósitos de tecido adiposo estáo aumentadas, com consequente aumento do peso desses tecidos. Além disso, a eficiência alimentar aumentada, devido à dieta hiperlipídica, demonstra alta eficiência com que os lipídios são estocados nos tecidos, o que pode também ter contribuído com o aumento da área de adipócitos.

Os dois tipos de treinamento foram eficientes para diminuir o peso relativo do tecido adiposo epididimal nos animais alimentados com dieta hiperlipídica. Já o treinamento de natação aumentou o peso relativo do TAM, independentemente das dietas. Dados similares foram encontrados por Xu et al. ${ }^{27}$, o qual verificou além do aumento do peso do TAM, também aumento das células progenitoras dos adipócitos marrons, aumento na expressão de genes específicos para esses adipócitos e aumento da UCP1, o que leva ao aumento do processo de fosforilação oxidativa e a dissipação de energia em forma de calor. Esses dados sugerem que o exercício pode levar a uma maior funcionalidade do tecido adiposo marrom, já que é considerado um tecido termogênico, responsável pela geração rápida de calor, e que é estimulado pela administração de hormônio da tireóide, pelo exercício através da estimulação do sistema nervoso simpático, pelo frio, ingestão alimentar e pela leptina ${ }^{28-30}$. O treinamento em natação não reduziu a área de adipócitos do tecido adiposo visceral. Estes achados também são semelhantes com os estudos de SEne-Fiorese et al. ${ }^{21}$ e Gollisch et al. $^{31}$, que não observaram redução no peso relativo, como também na área de adipócitos do tecido adiposo visceral após várias semanas de treinamento aeróbio continuo em animais que se alimentavam com dieta hiperlipídica. Estes resultados sugerem uma maior mobilização de ácidos graxos livres (AGL) por outros tecidos adiposos em detrimento do tecido adiposo visceral durante o exercício de natação. Uma explicação para estes resultados pode ser o tempo de exercício contínuo (60min), já que SENE-FIOREse et al. ${ }^{21}$ também observou que o exercício contínuo, porém 90 minutos, também não apresentou redução no peso do tecido adiposo visceral. Talvez, o exercício contínuo com essas duraçôes não sejam capazes de mobilizar os AGL de tal tecido. Outra explicação talvez seja a carga utilizada no treinamento ( $5 \%$ da massa corporal dos ratos), considerada o ponto de transição entre o metabolismo aeróbio e anaeróbio em ratos, segundo Gоватто et al. ${ }^{32}$. Essa intensidade de exercício coincide com o aumento nos níveis de catecolaminas ${ }^{33}$. $\mathrm{O}$ tecido adiposo visceral é muito sensível às catecolaminas por apresentar maior número de receptores alfa e beta adrenérgicos ${ }^{34}$. Dessa maneira, é possível que a carga utilizada pelos ratos obesos durante a nataçáo não tenha sido suficiente para promover aumento significativo nos níveis de catecolaminas, resultando em uma menor mobilização dos lipídeos provenientes do tecido adiposo visceral durante o exercício de natação. Assim, parece que o tempo e a carga utilizada no treinamento foram limitaçóes para este estudo quanto ao treinamento em natação.

A dieta rica em gorduras aumenta a chance de desenvolver esteatose hepática não alcoólica. Esta, é caracterizada, principalmente, pelo acúmulo de gordura no fígado, devido à diminuição na oxidação das gorduras neste tecido, ou pela redução na exportação dos triacilgliceróis (TG) pela lipoproteína de muito baixa densidade (VLDL) a partir do próprio fígado ${ }^{35,37}$, também observado em nosso estudo. Lladó et al. ${ }^{38}$, observaram que em ratos alimentados com dieta hiperlipídica durante 15 dias tiveram maior conteúdo lipídico nos tecidos adiposos, devido à redução da atividade lipolítica nestes tecidos o que pode explicar o aumento do conteúdo lipídico e peso relativo dos tecidos adiposos, em nosso estudo.

No entanto, os dois tipos de treinamentos foram eficientes para diminuir a gordura do fígado e, o treinamento em natação também contribuiu com a diminuição do conteúdo lipídico do tecido adiposo retroperitoneal, o que condiz com a menor área de adipócitos observada nesses animais. Existem evidências de que o treinamento de força estimula a oxidação lipídica no fígado devido a ativação da via da $\mathrm{AMPK}^{15,38,39}$ e regulação negativa de enzimas lipogênicas pela expressão de genes hepáticos ${ }^{40}$, já que a AMPK fosforila diversas proteínas que aumentam as taxas de glicose e ácidos graxos para corrigir o déficit de ATP que ocorre durante um estresse metabólico, como por exemplo, o exercício. Provavelmente isso explique a diminuição do conteúdo lipídico no fígado dos animais exercitados. A ativação da AMPK ainda pode ter influenciado a diminuição do conteúdo lipídico dos tecidos adiposos, estimulando a oxidação de gordura durante e após o exercício ${ }^{39,41}$.

Como discutido acima, nosso estudo mostrou que a dieta hiperlipídica, leva ao aumento dos depósitos de gordura, aumento do conteúdo lipídico dos tecidos 
e desenvolvimento de dislipidemias. No entanto, vale ressaltar que esse tipo de dieta também foi capaz de estimular o sistema endocanabinóide (SE) pelo aumento da expressão dos receptores CB1 no tecido adiposo visceral. Dieta hiperlípídica e alimentos palatáveis levam ao desequilíbrio do SE, alterando o 2-AG, a anandamida e a expressão do receptor CB1 em diversos tecidos, inclusive o tecido adiposo visceral ${ }^{19,42,43}$. Nossos resultados demonstram expressão gênica aumentada para CB1 que, são condizentes com os valores de área de adipócito aumentada no tecido adiposo visceral. Apesar da expressão do PPAR $\gamma$ não ter sido estatisticamente significante, o aumento de 2,6 vezes no grupo que se alimentou com dieta hiperlipídica, em relação ao grupo dieta padrão, sugere possível estimulo dos receptores $\operatorname{PPAR} \gamma$, pelo SE, o que leva ao acúmulo de lipídios no tecido, como observado em nosso estudo. Além disso, o SE também estimula a atividade da LPL, aumentando a lipogênese e acúmulo de lipídios nos adipócitos ${ }^{44}$, o que pode ter ocorrido em nosso estudo. Petridou et al. ${ }^{45}$, estudando o efeito do exercício crônico sobre a expressão do PPAR $\gamma$, em diferentes tecidos, verificaram aumento na atividade transcricional do PPAR $\gamma$ no tecido adiposo.

É sabido que o aumento da atividade transcricional desse fator é importante por contribuir para o aumento da sensibilidade à insulina ${ }^{46}$. Assim, pode ser que, apesar de nossos resultados náo apresentarem aumento na expressão do PPAR $\gamma$, sua atividade transcricional esteja aumentada, contribuindo para aumento da sensibilidade à insulina com consequente aumento na captação de glicose, levando ao aumento de lipídios nos adipócitos.

Existem evidências clínicas e experimentais que indicam que em comparaçáo com outros tecidos adiposos, o visceral é o mais prejudicial, já que ele apresenta características que aumentam o risco cardiovascular em pacientes obesos e com síndrome metabólica ${ }^{47}$. E a expressão aumentada de CB1 neste tecido parece desempenhar importante papel no desenvolvimento da obesidade48. Interessantemente, observamos que os ambos protocolos de treinamento foram capazes de minimizar os efeitos da dieta hiperlipídica sobre a expressão do receptor CB1 no tecido adiposo visceral, já que os grupos treinados apresentaram menores valores na expressão desse gene, reduzindo assim os efeitos negativos do SE sobre o tecido adiposo visceral, corroborando com o estudo de YAn et al. ${ }^{19}$.

Vale ressaltar que o sistema endocanabinóide participa na regulação da ingestão alimentar e gasto energético a nível central e periférico ligado a uma complexa rede de sinalizaçáo que envolve mediadores anorexígenos e orexígenos, como a leptina e grelina ${ }^{8,49}$. Estudos indicam o CB1 como principal receptor atuando na regulação do apetite, sensibilidade à insulina e metabolismo lipídico ${ }^{50,51}$. O estímulo do SE por um agonista do CB1 no tecido adiposo visceral aumentou a capacidade de captação de glicose ${ }^{52-53}$ e a expressão da ácido graxo sintetase, responsável pelo aumento da síntese "de novo" de ácido graxo, levando ao aumento do conteúdo lipídico no fígado ${ }^{54}$. Nossos resultados corroboram com tais estudos já que houve aumento no conteúdo lipídico no fígado dos animais obesos com aumento na expressão de CB1, indicando que a dieta hiperlipídica estimulou o SE levando ao acúmulo de lipídios.

Finalmente, de acordo com o desenho experimental e os resultados obtidos, o presente estudo permite concluir que os protocolos de treinamento em natação e força são importantes estratégias não-farmacológicas no controle dos efeitos deletérios da dieta hiperlipídica e obesidade. Esses achados levantam perspectivas clínicas interessantes para prevenir os efeitos da obesidade através do treinamento físico, principalmente em relação ao treinamento de força, já que existem poucos estudos sobre esse tipo de exercício no quadro de obesidade.

\section{Conflito de interesses}

Os autores declaram não ter nenhum conflito de interesse.

\section{Agradecimentos}

Suporte financeiro: Conselho Nacional de Desenvolvimento Científico e Tecnológico (CNPq) e Coordenação de Aperfeiçoamento de Pessoal de Nível Superior (CAPES), Brasil. 


\section{Abstract}

Influence of different exercise protocols and hyperlipid diet on the endocanabinoid system of rats

The objective of the study was to investigate the effects of the hyperlipid diet and the training of swimming and force on the adipose tissue, lipid profile and endocannabinoid system of exogenous obese rats. For this, we used sixty adult male rats divided into six groups: Sedentary Standard (SP); Sedentary Hyperlipid (SH); Standard Swimming (NP); Hyperlipid Swimming (NH); Standard Force (FP); Hyperlipid Force (FH). After three weeks receiving standard or hyperlipidic diet, the animals started the exercise protocols. The NP and NH groups swam 60 minutes/day, 5 days/week with 5\% body weight binding to the body, in 50x30 cm tanks, for 8 weeks. The FP and FH groups performed ladder climbing exercises with weights tied to their tails, once every three days, for 8 weeks. Animals from the SP and SH groups remained sedentary and fed their respective diets. The hyperlipid diet increased body weight gain, relative weight of adipose (epididimal, retroperitoneal, visceral and subcutaneous) and adipocyte (epididimal, retroperitoneal and visceral) areas. It also increased the fat percentage of all adipose tissues and liver, in addition to increasing the gene expression of the CB1 receptor. The trained groups had lower values of adipocyte area, improvement of lipid profile, lower values in fat percentage of adipose tissues and liver, lower gains of body mass, and lower gene expression of CB1 receptor. Thus our results indicate the potential benefits of strength and swimming training as non-pharmacological alternatives to control the deleterious effects of the hyperlipidic diet on adipose tissue, lipid profile, lipid content and control of the imbalance of the endocannabinoid system caused by the hyperlipidic diet.

KEYWORDS: Obesity; Strength training; Swimming; CB1 receptor; Endocannabinoid system.

\section{Referências}

1. Richey JM, Woolcott O. Re-visiting the endocannabinoid system and its therapeutic potential in obesity and associated diseases. Curr Diab Rep. 2017;14:1-7.

2. Silvestri C, Di Marzo V. The endocannabinoid system in energy homeostasis and the etiopathology of metabolic disorders. Cell Metabolism. 2013;17(2):475-490.

3. Lau BK, Cota D, Cristino L, Borgland SL. Endocannabinoid modulation of homeostatic and non-homeostatic feeding circuits. Neuropharmacol. 2017;24(15):38-51.

4. Bennetzen MF. Investigations of the endocannabinoid system in adipose tissue: effects of obesity/ weight loss and treatment options. Dan Med Bull. 2011;58(4):B4269.

5. Bellocchio L, Cervino C, Pasquali R, Pagotto U. The endocannabinoid system and energy metabolism. J Neuroendocrinol. 2008;20:850-857.

6. Matias I, Patrosino S, Racioppi A. et al. Dysregulation of peripheral endocannabinoid levels in hyperglycemia and obesity: Effect of high fat diets. Mol Cell Endocrinol. 2008;286:66-78.

7. Di Marzo V, Cote M, Matias I, Lemieux I, Arsenault BJ, Cartier A, et al. Changes in plasma endocannabinoid levels in viscerally obese men following a 1 year lifestyle modification programme and waist circumference reduction: associations with changes in metabolic risk factors. Diabetol. 2009;52(2):213-7.

8. Arnone M, Maruani J, Chaperon Fet al. Selective inhibition of sucrose and ethanol intake by SR 141716, an antagonist of central cannabinoid CB1 receptors. Psychopharmacol. 1997;132:104-106.

9. Cota D, Marsicano G, Tschop $\mathrm{M}$ et al. The endogenous cannabinoid system affects energy balance via central orexigenic drive and peripheral lipogenesis. J Clin Invest. 2003;112:423-31.

10. Di Marzo V, Goparaju SK, Wang L. et al. Leptin-regulated endocannabinoids are involved in maintaining food intake. Nature. 2001;410:822-825.

11. Wajchenberg BL, Giannella-Neto D, Silva MER et al. Specific hormonal characteristics of subcutaneous and visceral adipose tissue and their relation to the metabolic syndrome. Horm Metab Res. 2002;34:616-21.

12. Stienstra R, Duval C, Muller M. et al. PPARs, Obesity, and Inflammation. PPAR Research. 2007;2007:959-74.

13. Ferre P. The biology of peroxisome proliferator-activated receptors: relationship with lipid metabolism and insulin 
sensitivity. Diabetes. 2004;53:43-50.

14. Upadhyay J, Farr O, Perakakis N, Ghaly W, Mantzoros C. Obesity as a disease. Med Clin North Am. 2018;102(1):1333.

15. Corriveau P, Paquette A, Brochu M, et al. Resistance training prevents liver fat accumulation in ovariectomized rats. Maturitas. 2008;59: 259-67.

16. Leite RD, Prestes, J, Bernardes, CF et al. Effects of ovariectomy and resistance training on lipid content in skeletal muscle, liver, and heart; fat depots; and lipid profile. Appl Physiol Nutr Metab. 2009;34:1079-86.

17. Pighon A, Paquette A, Barsalani R, et al. Substituting food restriction by resistance training prevents liver and body fat regain in ovariectomized rats. Climacteric. 2009;12:153-64.

18. Gomes da silva S, Araújo BHS, Cossa AC, et al. Physical exercise in adolescence changes CB1 cannabinoid receptor expressionin the rat brain. Neurochem Intern. 2010;57:492-496.

19. Yan AC, Liu DY, Zhang LL, et al. Exercise reduces adipose tissue via cannabinoid receptor type 1 which is regulated by peroxisome proliferator-activated receptor- $\partial$. Rev Biochem Biophys Res Commun. 2007; 354:427-433.

20. Duarte FO, Sene-Fiorese M, Cheick NC, et al. Food restriction and refeeding induces changes in lipid pathways and fat deposition in the adipose and hepatic tissues in rats with diet-induced obesity. Exp Physiol. 2012;97(7):882-894.

21. Sene-Fiorese M, Duarte FO, Scarmagnani FRR, et al. Efficiency of intermittent exercise on adiposity and fatty liver in rats fed with high-fat diet. Obesity Res. 2008;16:2217-2222.

22. Hornberger TA, Farrar RP. Physiological hypertrophy of the FHL muscle following 8 weeks of progressive resistance exercise in the rat. Can J Appl. Physiol. 2004;29:16-31.

23. Hirsch J, Gallian E. Methods for determination of adipose cell size in man and animals. J Lipid Res. 1968;9:110-19.

24. Stansbie, D, Brownsey, RW, Crettaz M, Denton RM. Acute effects in vivo of anti-insulin serum on rates of fatty acid synthesis and activities of acetyl-coenzyme A carboxylase and pyruvate dehydrogenase in liver and epididymal adipose tissue of fed rats. Biochem J. 1976;160(2):413-416.

25. Washington MC, Coggeshall J, Sayegh AI. Cholecystokinin-33 inhibits meal size and prolongs the subsequent intermeal interval. Peptides. 2011;32:971-7.

26. Castellano-Castillo D, Moreno-Indias I, Fernández-García JC, et al. Adipose tissue LPL methylation is associated with triglyceride concentrations in the metabolic syndrome. Clin Chem. 2018;64(1):210-218.

27. Xu X, Ying X, Cai M, et al. Exercise ameliorates high-fat diet-induced metabolic and vascular dysfunction, and increases adipocyte progenitor cell population in brown adipose tissue. Am J Physiol Regul Integr Comp Physiol. 2011;300; 1115-1125.

28. Symonds ME, Mostyn A, Pearce S, et al. Endocrine and nutritional regulation of fetal adipose tissue development. J Endocrinol. 2003;179:293-299.

29. Sell H, Deshaies Y, Richard D. The brown adipocyte: update on its metabolic role. Int J Bioch Cell Biol. 2004; 36: 2098-2104.

30. Westerterp KR. Diet-induced thermogenesis. Nutr Metab. 2004;1:1-5.

31. Gollisch KS, Brandauer J, Jessen N, et al. Effects of exercise training on subcutaneous and visceral adipose tissue in normal- and high-fat diet-fed rats. Am J Physiol Endocrinol Metab. 2009;297:495-504.

32. Gobatto CA, De Mello MA, Sibuya CY, et al. Maximal lactate steady state in rats submitted to swimming exercise. Comp Biochem Physiol A Mol Integr Physiol. 2001;130:21-7.

33. Simoes HG, Campbell CS, Kushnick MR, et al. Blood glucose threshold and the metabolic responses to incremental exercise tests with and without prior lactic acidosis induction. Eur J Appl Physiol. 2003;89:603-11.

34. Hansen D, Dendale P, Berger J, et al. The effects of exercise training on fat-mass loss in obese patients during energy intake restriction. Sports Med. 2007;37:31-46.

35. Bravo E, Palleschi S, Aspichueta P, et al. High fat diet-induced nonalcoholic fatty liver disease in rats is associated with hyperhomocysteinemia caused by down regulation of the transsulphuration pathway. Lipids Health Dis. 2011;10:60.

36. Stanton MC, Chen SC, Jackson JV, et al. Inflammatory Signals shift from adipose to liver during high fat feeding and influence the development of steatohepatitis in mice. J Inflamm. 2011;8:1-8.

37. Lladó I, Rodriguez-Cuenca S, Pujol E, et al. Gender effects on adrenergic receptor expression and lipolysis in white adipose tissue of rats. Obesity Res. 2002;10:296-305.

38. Park H, Kaushik VK, Constant S, et al. Coordinate regulation of malonyl-CoA decarboxylase, sn-glycerol-3-phosphate acyl-transferase, and acetyl-CoA carboxylase by AMP-activated pro-tein kinase in rat tissues in response to exercise. J Biol Chem. 2002;36:32571-577. 
39. Lavoie JM, Gauthier MS, Regulation of fat metabolism in the liver: link to non-alcoholic hepatic steatosis and impact of physical exercise. Cell Mol Life Sci. 2006;12:1393-1998.

40. Paquette A, Wang D, Jankowski M, et al. Effects of ovariectomy on PPAR alpha, SREBP-1c, and SCD-1 gene expression in the rat liver. Menopause. 2008; 6:1169-1175.

41. Hallsworth K, Fattakhova G, Hollingsworth KG, et al. Resistance exercise reduces liver fat and its mediators in nonalcoholic fatty liver disease independent of weight loss. Gut. 2011;60:1278-1283.

42. Ravinet Trillou C, Delgorge C, Menet C, et al. CB1 cannabinoid receptor knockout in mice leads to leanness, resistance to diet-induced obesity and enhanced leptin sensitivity. Int J Obesity. 2004;28:640-648.

43. Engeli S. Dysregulation of the endocannabinoid system in obesity. J Neuroendocrinol. 2008;20:110-115.

44. Cota D, Marsicano G, Tschop M, et al. The endogenous cannabinoid system affects energy balance via central orexigenic drive and peripheral lipogenesis. J Clin Invest. 2003;112:423-31.

45. Petridou A, Tsalouhidou S, Tsalis G, et al. Long-term exercise increases the DNA binding activity of peroxisome proliferator-activated receptor gamma in rat adipose tissue. Metabolism. 2007;56:1029-36.

46. Gurnell M. Peroxisome proliferator-activated receptor $\gamma$ and the regulation of adipocyte function: lessons from human genetic studies. Best Pract Res Clin Endocrinol Metab. 2005;19:501-23.

47. Storz C, Heber SD, Rospleszcz S, et al. The role of visceral and subcutaneous adipose tissue measurements and their ratio by magnetic resonance imaging in subjects with prediabetes, diabetes and healthy controls from a general population without cardiovascular disease. Br J Radiol. 2018;19:20170808.

48. Kim J, Li Y, Watkins BA Endocannabinoid signaling and energy metabolism: a target for dietary intervention. Nutrition. 2011;27(6):624-32.

49. Kola B, Farkas I, Christ-Crain M, et al. The orexigenic effect of ghrelin is mediated through central activation of the endogenous cannabinoid system. Plos One. 2008;3:1797.

50. Williams CM, Kirkham TC. Anandamide induces overeating: mediation by central cannabinoid (CB1) receptors. Psychopharmacol. 1999;143:315-7.

51. Kirkham TC, Williams CM, Fezza F, Di Marzo V. Endocannabinoid levels in rat limbic forebrain and hypothalamus in relation to fasting, feedind and satiation: stimulation of eating by 2 -arachidonoyl glycerol. $\mathrm{Br} \mathrm{J}$ Pharmacol. 2002; 136:550-557.

52. Pagano C, Pilo C, Calcagno A, et al. The Endogenous Cannabinoid System Stimulates Glucose Uptake in human fat cells via phosphatidylinositol 3-kinase and calcium-dependent mechanisms. J Clin Endocrinol Metab. 2007; 92:48104819.

53. Motaghedi R, McGraw TE. The CB1 endocannabinoid system modulates adipocyte insulin sensitivity. Obesity. 2008; 8:1727-34.

54. Osei-Hyiaman D, Depetrillo M, Pacher P, et al. Endocannabinoid activation at hepatic CB1 receptors stimulates fatty acid synthesis and contributes to diet-induced obesity. J Clin Invest. 2005;115:1298-1305.
ENDEREÇO
Diego Adorna Marine
R. Flauzino Marques 67, Apto 14 - Bl. B - Jardim Alvorada
Submetido: $31 / 08 / 2017$
Revisado: 09/03/2018
13562-002 - São Carlos - SP - Brasil
Aceito: 07/05/2018
E-mail: diegomarine@gmail.com 